\title{
BMJ
}

\section{The health and socioeconomic impacts of major multi-sport events: systematic review (1978-2008)}

\author{
Gerry McCartney, specialist registrar in public health, ${ }^{1}$ Sian Thomas, systematic reviewer, ${ }^{2}$ Hilary Thomson, \\ senior investigator scientist, John Scott, public health librarian, ${ }^{3}$ Val Hamilton, freelance information scientist, ${ }^{4}$ \\ Phil Hanlon, professor of public health, ${ }^{5}$ David S Morrison, clinical senior lecturer in cancer epidemiology and \\ director, ${ }^{6}$ Lyndal Bond, professor and associate director ${ }^{1}$
}

\section{ABSTRACT}

Objective To assess the effects of major multi-sport events on health and socioeconomic determinants of health in the population of the city hosting the event. Design Systematic review.

Data sources We searched the following sources without language restrictions for papers published between 1978 and 2008: Applied Social Science Index and Abstracts (ASSIA), British Humanities Index (BHI), Cochrane database of systematic reviews, Econlit database, Embase, Education Resources Information Center (ERIC) database, Health Management Information Consortium (HMIC) database, International Bibliography of the Social Sciences (IBSS), Medline, PreMedline, PsycINFO, Sociological Abstracts, Sportdiscus, Web of Knowledge, Worldwide Political Science Abstracts, and the grey literature.

Review methods Studies of any design that assessed the health and socioeconomic impacts of major multi-sport events on the host population were included. We excluded studies that used exclusively estimated data rather than actual data, that investigated host population support for an event or media portrayals of host cities, or that described new physical infrastructure. Studies were selected and critically appraised by two independent reviewers.

Results Fifty four studies were included. Study quality was poor, with $69 \%$ of studies using a repeat cross-sectional design and $85 \%$ of quantitative studies assessed as being below $2+$ on the Health Development Agency appraisal scale, often because of a lack of comparison group. Five studies, each with a high risk of bias, reported health related outcomes, which were suicide, paediatric health service demand, presentations for asthma in children (two studies), and problems related to illicit drug use. Overall, the data did not indicate clear negative or positive health impacts of major multi-sport events on host populations. The most frequently reported outcomes were economic outcomes (18 studies). The outcomes used were similar enough to allow us to perform a narrative synthesis, but the overall impact of major multisport events on economic growth and employment was unclear. Two thirds of the economic studies reported increased economic growth or employment immediately after the event, but all these studies used some estimated data in their models, failed to account for opportunity costs, or examined only short term effects. Outcomes for transport were also similar enough to allow synthesis of six of the eight studies, which showed that event related interventions-including restricted car use and public transport promotion-were associated with significant short term reductions in traffic volume, congestion, or pollution in four out of five cities.

Conclusions The available evidence is not sufficient to confirm or refute expectations about the health or socioeconomic benefits for the host population of previous major multi-sport events. Future events such as the 2012 Olympic Games and Paralympic Games, or the 2014 Commonwealth Games, cannot be expected to automatically provide benefits. Until decision makers include robust, long term evaluations as part of their design and implementation of events, it is unclear how the costs of major multi-sport events can be justified in terms of benefits to the host population.

\section{INTRODUCTION}

In 2012 the Olympic Games and the Paralympic Games will take place in London, and in 2014 the Commonwealth Games will be hosted by Glasgow. A major consideration in bidding to host the events in London and Glasgow was the potential for the games to generate a wide range of benefits for the population of the host city. ${ }^{1-4}$ Such purported benefits - collectively termed the "legacy"-include improvements in employment levels, the economy, housing, national and local pride, the environment, and sports provision. These outcomes represent key socioeconomic determinants of health, ${ }^{5}$ which suggests that the investment has the potential to improve health.

Detailed theories of how the legacy of hosting the games might influence health were outlined in the Department of Health's recent review of the potential physical activity and health legacy from the London 2012 Olympic Games and Paralympic Games, ${ }^{6}$ and in the Scottish Government's 2014 Commonwealth Games legacy consultation document. ${ }^{3}$ The likelihood 
of benefits arising from major sports events and the relative cost has been re-examined since, however, and the previous Olympics minister for the United Kingdom, Tessa Jowell, has said, "Had we known what we know now, would we have bid for the Olympics? Almost certainly not."7

A large amount of research on the impact of major sports events on host populations is available, ${ }^{8}$ but this body of research has not been systematically brought together to allow decision makers to make informed judgments on the basis of the known effects and the known areas of uncertainty. ${ }^{9}$ The aim of this systematic review was to assess the impact of major sporting events (1978-2008) on the health, and the determinants of health, of the host population.

\section{METHODS}

We designed the review and published a brief online protocol in March 2008. ${ }^{10}$

\section{Data sources and searches}

During February and March 2008, we searched without language restrictions the following sources for articles published between 1978 and 2008: Applied Social Science Index and Abstracts (ASSIA); British Humanities Index (BHI); Cochrane database of systematic reviews; Econlit database; Embase; Education Resources Information Center (ERIC) database; Health Management Information Consortium (HMIC) database; International Bibliography of the Social Sciences (IBSS); Medline; PreMedline; PsycINFO; Sociological Abstracts; Sportdiscus; Web of Knowledge; and Worldwide Political Science Abstracts.

An extensive search of the "grey literature" was conducted between April 2008 and October 2008 using the following resources: BUBL; Centre for Education

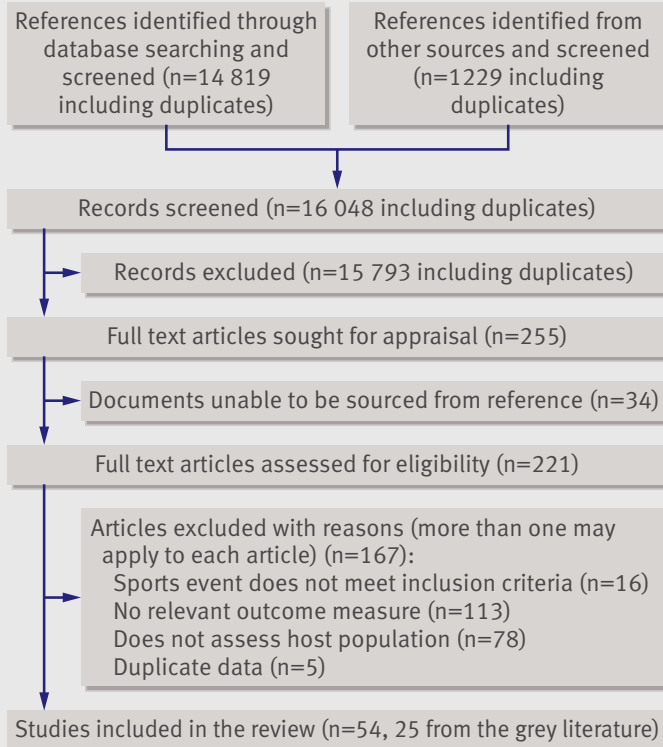

Articles excluded with reasons (more than one may apply to each article) $(n=167)$

Sports event does not meet inclusion criteria $(n=16)$

No relevant outcome measure $(n=113)$

Does not assess host population $(\mathrm{n}=78)$

Duplicate data $(n=5)$

tudies included in the review ( $n=54,25$ from the grey literature)

Results of the literature search in the Built Environment (CEBE); Chartered Institute of Housing (CHI); Copac National, Academic, and Specialist Library Catalogue; Economic and Social Research Council (ESRC) Society Today; Google; IDOX information services; Index to Theses in Great Britain and Ireland; US Department of Housing and Urban Development (HUD); Intute; Proquest Dissertations and Theses database; Royal Town Planning Institute; Sapling.info; Scirus; System for Information on Grey Literature in Europe (SIGLE); Transportation Research Information Service (TRIS); Urban Age; and WorldCat. There was no restriction on the publication date or language.

The search terms we used are detailed in web table A. The reference lists and bibliographies of all the included articles and reviews were searched by hand. A request for relevant studies was distributed using the International Society for Urban Health newsletter and UK and international email lists for health impact assessments.

\section{Study inclusion criteria}

We included studies of any design that had investigated the impact on the host population of any "one off," international, multi-sport event focused on a single city or area that took place between January 1978 and January 2008. We did not include earlier events because of the increasing focus by host cities on the potential for legacy - rather than national showcasing -after $1978 .^{1}$

We included outcomes relating to health, wellbeing, quality of life, health service use, and physical activity or functioning, and any measures of the socioeconomic determinants of health as described by Dahlgren and Whitehead, ${ }^{5}$ including access to services and transport, environment, crime, housing, demography, and cultural and economic outcomes. Studies exclusively investigating the impacts on visitors, athletes, or spectators; the host population's support for the event; the non-host population's opinions about the host area media portrayals of the event; and economic impacts by using exclusively estimated data were excluded. Studies that used a mix of real and estimated data were included. Commentaries that did not present original data or analysis were not included in the review. Simple lists of construction activity related to events (for example, new stadia) were not included, although studies describing the impact of construction on any of the determinants of health (for example, access to facilities or economic growth) were included.

Study selection, assessment of study quality, and data extraction

Two reviewers independently screened all references identified by the searches before duplicates were removed. Studies that were identified as potentially relevant were then retrieved where possible and independently screened for relevance.

All retrieved studies were critically appraised independently by two reviewers. Disagreements were 
Table 1| Impacts of major multi-sport events on health and determinants of health

\begin{tabular}{|c|c|c|c|c|}
\hline Study & $\begin{array}{c}\text { Level of } \\
\text { evidence* }\end{array}$ & Event & Outcome & Impact $†$ \\
\hline \multicolumn{5}{|l|}{ Health } \\
\hline $\mathrm{Lee}^{17}$ & $2+$ & $\begin{array}{l}2002 \text { AG Busan, South } \\
\text { Korea }\end{array}$ & $\begin{array}{c}\text { Childhood asthma hospital } \\
\text { admissions }\end{array}$ & $\leftrightarrow$ \\
\hline Friedman $^{18}$ & $2-$ & 1996 OG Atlanta, GA, USA & $\begin{array}{c}\text { Childhood asthma acute care } \\
\text { events }\end{array}$ & $\downarrow$ \\
\hline $\operatorname{Shin}^{16}$ & $2+$ & $\begin{array}{l}1988 \text { OG Seoul, South } \\
\text { Korea }\end{array}$ & Suicide rates & $\leftrightarrow$ \\
\hline $\operatorname{lndig}^{20}$ & $2-$ & 2000 OG Sydney, Australia & $\begin{array}{l}\text { Hospital presentations related } \\
\text { to illicit drugs }\end{array}$ & $\uparrow$ \\
\hline Simon $^{19}$ & $2-$ & 1996 OG Atlanta & $\begin{array}{l}\text { Paediatric health service } \\
\text { demand }\end{array}$ & $\uparrow$ \\
\hline
\end{tabular}

\begin{tabular}{|c|c|c|c|c|}
\hline \multicolumn{5}{|l|}{ Recreation } \\
\hline Brown $^{23}$ & Qualitative & 2002 CG Manchester, UK & $\begin{array}{l}\text { Legacy programme } \\
\text { implementation }\end{array}$ & $\mathrm{N} / \mathrm{A}$ \\
\hline $\mathrm{MORI}^{21}$ & $2-$ & 2002 CG Manchester & Sports participation & $\downarrow$ \\
\hline Truno $^{22}$ & $2-$ & 1992 OG Barcelona, Spain & Sports participation & $\uparrow$ \\
\hline Newby $^{24}$ & $2-$ & 2002 CG Manchester & Satisfaction with green spaces & $\uparrow$ \\
\hline \multicolumn{5}{|c|}{ Transport and the environment } \\
\hline $\operatorname{Lee}^{17}$ & $2+$ & 2002 AG Busan & Air pollution & $\downarrow$ \\
\hline Potter $^{47}$ & $2+$ & 1996 OG Atlanta & Road traffic volume & $\downarrow$ \\
\hline \multirow{2}{*}{ Fidell $^{52}$} & \multirow{2}{*}{ 2- } & \multirow{2}{*}{1996 OG Atlanta } & Airport noise episodes & $\uparrow$ \\
\hline & & & Night time awakenings & $\uparrow$ \\
\hline \multirow{2}{*}{ Friedman $^{18}$} & \multirow{2}{*}{ 2- } & \multirow{2}{*}{1996 OG Atlanta } & Air pollution & $\downarrow$ \\
\hline & & & Road traffic volume & $\downarrow$ \\
\hline Giuliano $^{49}$ & $2-$ & $\begin{array}{c}1984 \text { OG Los Angeles, CA, } \\
\text { USA }\end{array}$ & Car commuting journey time & $\downarrow$ \\
\hline Hallenbeck $^{50}$ & 2- & 1990 GWG Seattle, WA, USA & Road traffic volume & $\leftrightarrow$ \\
\hline Hensher $^{51}$ & $2-$ & 2000 OG Sydney & Commuting journey time & $\downarrow$ \\
\hline \multirow{2}{*}{$\mathrm{Lee}^{48}$} & \multirow{2}{*}{$2-$} & \multirow{2}{*}{2002 AG Busan } & Air pollution & $\uparrow$ \\
\hline & & & Road traffic volume & $\downarrow$ \\
\hline
\end{tabular}

Crime, housing, and demography

\begin{tabular}{|c|c|c|c|c|}
\hline \multirow{2}{*}{ Decker $^{56}$} & \multirow{2}{*}{$2+$} & \multirow{2}{*}{1996 OG Atlanta } & Demand for police services & $\uparrow$ \\
\hline & & & Recorded crime & $\downarrow$ \\
\hline Brunet $^{39}$ & $2-$ & 1992 OG Barcelona & House prices & $\uparrow$ \\
\hline Halifax Plc ${ }^{57}$ & $2-$ & 1992-2004 OG & House prices & $\uparrow$ \\
\hline Hiller $^{58}$ & $2-$ & $\begin{array}{l}1988 \text { WO Calgary, AB, } \\
\text { Canada }\end{array}$ & $\begin{array}{l}\text { Population of immediate host } \\
\text { area }\end{array}$ & $\downarrow$ \\
\hline Hopkins $^{59}$ & $2-$ & 1996 OG Atlanta & $\begin{array}{l}\text { "Urban camping law" } \\
\text { introduction }\end{array}$ & $\mathrm{N} / \mathrm{A}$ \\
\hline $\begin{array}{l}\text { Greater London } \\
\text { Authority }\end{array}$ & $2-$ & 1992-2004 OG & House prices & $\uparrow$ \\
\hline \multirow{4}{*}{ Newby $^{24}$} & \multirow{4}{*}{ 2- } & \multirow{4}{*}{2002 CG Manchester } & Perceived supermarket access & $\uparrow$ \\
\hline & & & Satisfaction with local area & $\uparrow$ \\
\hline & & & $\begin{array}{l}\text { Satisfaction with house and its } \\
\text { condition }\end{array}$ & $\uparrow$ \\
\hline & & & $\begin{array}{l}\text { Reported vandalism to own } \\
\text { property }\end{array}$ & $\downarrow$ \\
\hline Lybbert $^{32}$ & $2-$ & $\begin{array}{c}1980 \text { and } 1988 \text { WO; } 1984 \\
\text { and } 1996 \text { OG }\end{array}$ & Migration to Olympic regions & $\uparrow$ \\
\hline \multicolumn{5}{|l|}{ Volunteers } \\
\hline \multirow{2}{*}{ Downward $^{54}$} & \multirow{2}{*}{ 2- } & \multirow{2}{*}{2002 CG Manchester } & $\begin{array}{l}\text { Volunteers' participation in } \\
\text { sport }\end{array}$ & $\leftrightarrow$ \\
\hline & & & $\begin{array}{l}\text { Likelihood of event volunteers } \\
\text { volunteering after event }\end{array}$ & $\leftrightarrow$ \\
\hline $\mathrm{Kemp}^{55}$ & $2-$ & $\begin{array}{l}1994 \text { WO Lillehammer, } \\
\text { Norway, and } 2000 \text { OG } \\
\text { Sydney }\end{array}$ & Perceived skills development & $\uparrow$ \\
\hline \multirow{3}{*}{ Lumsdon $^{53}$} & \multirow{3}{*}{ Qualitative } & \multirow{3}{*}{2002 CG Manchester } & Experience of event volunteers & $\uparrow \downarrow$ \\
\hline & & & $\begin{array}{c}\text { Volunteers' participation in } \\
\text { sport }\end{array}$ & $\leftrightarrow$ \\
\hline & & & $\begin{array}{l}\text { Volunteers' participation in } \\
\text { further voluntary work }\end{array}$ & $\leftrightarrow$ \\
\hline
\end{tabular}

\section{Culture}

\begin{tabular}{lcccc}
\hline Hargreaves $^{63}$ & $2-$ & 1992 OG Barcelona & Catalan identity & $\downarrow$ \\
\hline Kolstad $^{62}$ & $2-$ & 1994 WO Lillehammer & Adoption of Olympic values & $\leftrightarrow$ \\
\hline Waitt $^{61}$ & $2-$ & 2000 OG Sydney & Community spirit & $\uparrow$ \\
\cline { 4 - 5 } Owen $^{60}$ & Qualitative & 2000 OG Sydney & Local democracy & $\downarrow$
\end{tabular}

See web table $F$ for full critical appraisal and results for all included studies.

Abbreviations: AG, Asian Games; CG, Commonwealth Games; GWG, Goodwill Games; OG, Olympic Games; WO, Winter Olympic Games.

*Level of evidence as per web table $\mathrm{E}$.

$\dagger \uparrow=$ increase; $\downarrow=$ decrease; $\leftrightarrow=$ no change; $\uparrow \downarrow=$ mixed impacts for this outcome; N/A=not applicable (that is, the outcome cannot be described as a simple increase or decrease). resolved by discussion between reviewers. The quality of all the included studies was assessed using a modified version of the Hamilton quality assessment tool (web table B). ${ }^{12}$ Models that assessed economic impact were appraised with additional questions recommended by experts, because no relevant critical appraisal framework could be identified (web table C). Some economic studies used only real time data rather than a mix of real time and estimated data. Variations in data characteristics were part of the critical appraisal tool but were not reflected adequately in the overall grading, so an indication of the studies that used only real time data is provided in the synthesis. An additional set of appraisal questions based on the approach outlined by Dixon-Woods and colleagues was used for qualitative studies (web table D). ${ }^{13}$

A modified version of the Health Development Agency guidelines was used to classify the level of evidence reported in each quantitative study (ranging from $1++$ for the highest quality evidence to 4 for evidence based on expert opinion; web table E). ${ }^{14}$ The assignment of each level was on the basis of the design of the study and the risk of confounding, bias, or chance influencing the results, as determined by the critical appraisal. Those studies meeting all the critical appraisal criteria were classified as "high quality," and those meeting the majority of criteria and with a low risk of selection bias (criterion 2 in web table B) were defined as "well conducted."

\section{Data synthesis}

The data were tabulated with an indication of study quality and grouped into nine broad categories according to outcome studied: health; recreation; transport and environment; crime, housing, and demography; volunteers; culture; economics; business; and tourism (tables 1 and 2). Where there were multiple studies with similar outcome measures, the data were synthesised narratively using Economic and Social Research Council guidelines. ${ }^{15}$ Synthesis was possible for some outcomes relating to economic growth, employment, tourism and transport. Where there were studies of varying quality, greater emphasis was put on the results of the better quality studies. A range of other diverse outcomes were reported that were not amenable to synthesis; these outcomes have been summarised narratively. The available data were not amenable to formal testing for bias across studies.

\section{RESULTS}

Fifty four studies met the review criteria and were included in our analysis, 25 of which were obtained from the grey literature (figure). Thirty four potentially relevant studies were unobtainable (web extra 1). No systematic reviews were identified. The quality of the included studies was low and characterised by a high risk of bias: $69 \%$ of studies used a repeat cross-sectional design and $85 \%$ of quantitative studies were assessed as being below level $2+$ on the Health Development Agency scale for appraisal of study quality, often 
because of a lack of comparison group. The level of evidence of the included individual quantitative studies was either $2+(n=7)$ or $2-(n=41)$, whereas three of the studies from the grey literature were level 2+ and three were qualitative. A summary of the reported impacts is presented in tables 1 and 2, with more detailed data available in web table $\mathrm{F}$.

\section{Health impacts}

Only one study included assessment of a direct health impact (table 1). ${ }^{16}$ Shin and colleagues used a multivariate model to analyse the trends in suicide rates in Seoul, South Korea, during the 1988 Olympic Games (level 2+). They reported no change in the suicide rate.

During the 2002 Asian Games in Busan, South Korea, cars were restricted from entering the city on certain days by using car registration plate numbers as a rationing tool. One study (level $2+$ ) reported that paediatric hospital admissions for asthma declined in the three weeks after the Busan event compared with during the games period and the three weeks before the games (relative risk (RR) $0.73,95 \%$ confidence interval (CI) 0.49 to 1.11$).{ }^{17}$ This finding contrasted with the same period in the following year, in which hospital admissions increased compared with three weeks before and three weeks after (RR 1.78, 95\% CI 1.27 to 2.48). A study reporting a similar outcome in Atlanta, GA, USA, at the time of the 1996 Olympic Games compared paediatric hospital admissions for asthma during the games period with the four weeks before and four weeks after the games. ${ }^{18}$ The authors found decreases in care events by using a variety of markers of health service use: Medicaid claims (RR $0.61,95 \% \mathrm{CI} 0.44$ to 0.85 ), health maintenance organisation (US healthcare provider) claims (RR 0.56, 95\% CI 0.31 to 1.02), data from two paediatric hospitals (admissions decreased by $11.1 \%$ ), and data in the state of Georgia hospital discharge database (discharges decreased by 19.1\%). The reported decrease in paediatric asthma events in Atlanta was associated with a $22.5 \%$ decrease in peak traffic counts during the Olympic Games and a 27.9\% decrease in peak ozone levels in the city $(\mathrm{P}<0.001$ for both compared with 4 weeks before the start of the games).

Another study of the 1996 Olympic Games reported that 263 children from outside the local catchment area were seen at Atlanta hospitals around the time of the games (13 July to 13 August). ${ }^{19}$ The mean age of these children was 6.7 years, and $24 \%$ were seen in tertiary care centres and $76 \%$ in urgent care centres. The children originated from 23 countries and had 15 primary languages. A greater proportion of these 263 children required hospital admission during the event compared with local children $(27 \%$ v $13 \%$, respectively, at the tertiary hospital and 7\% $v 3 \%$, respectively, at the county hospital), and $44 \%$ of these children were uninsured.

A repeat cross-sectional study of presentations to hospital with problems induced by illicit drugs during the Olympic Games in Sydney, Australia, in 2000 and the two weeks before the games reported an increase in the mean daily number of presentations of 4.5 (from 8.8 to $13.3 ; \mathrm{P}=0.04) .{ }^{20}$ Presentations peaked 24 hours after the closing ceremony ( 35.0 per day) and were higher at weekends (16.6 $v$ with 9.2 during the week; $\mathrm{P}=0.001)$. Presentations of ecstasy related and amphetamine related problems increased during the games (daily mean of 5.1 compared with 1.7 during the two weeks before; $\mathrm{P}=0.007$ ) but the level of heroin related presentations was unchanged (daily mean of $4.5 \mathrm{com}-$ pared with $4.2 ; \mathrm{P}=0.8$ ). Australian residents comprised $90 \%$ of the presentations.

\section{Recreation impacts}

One study reported that overall sports participation (four or more times in the past four weeks, except walking) decreased in the Manchester area of the UK by $2 \%$ after the 2002 Commonwealth Games, and that the gap in participation rates between individuals in affluent areas and those in deprived areas widened significantly (table 1). ${ }^{21}$ On the other hand, there was an upward trend in sports participation from the early 1980s until 1994 in association with the 1992 Olympic Games in Barcelona, Spain. ${ }^{22}$

A second study examining the 2002 Commonwealth Games in Manchester suggested that it was difficult to reap sports legacy gains in this case because of problems with funding and capacity, the exclusion of voluntary groups from using event branding, and a failure to retain key staff after the games. It was also suggested that the provision of new sports facilities benefited elite athletes after the event more than the host population. ${ }^{23}$ However, satisfaction with green spaces in Manchester did increase after the event (from $28 \%$ to $75 \%$ ). ${ }^{24}$

\section{Economic impacts}

The outcomes most commonly assessed in studies on the impacts of major multi-sports events were economic growth and employment (table 2). Although most studies associated major multi-sports events with increased economic growth and employment, these studies often used largely estimated data, had a very short post-event data collection period, and failed to take account of the opportunity costs of hosting large events, thus limiting the validity of the overall results. ${ }^{24-36}$

Some of the studies with longer data collection periods, less estimated data, and more collected data described some negative growth and detrimental impacts on employment. ${ }^{323738}$ Inflation increased in Barcelona ${ }^{3139}$ and Atlanta, ${ }^{31}$ but not in Sydney, ${ }^{3140}$ in the run up to hosting the Olympic Games. Investment in sports infrastructure in Sydney was associated with a delay in health and education capital investment. ${ }^{41}$

Two studies reported that becoming a host city for the Olympic Games was associated with higher investment, as approximated by increased stock market indices. ${ }^{4243}$ Two qualitative studies of business development activity at the Sydney Olympic Games in 2000 
Table 2 | Impacts of major multi-sport events on the economic determinants of health

\begin{tabular}{|c|c|c|c|c|}
\hline Study & $\begin{array}{c}\text { Level of } \\
\text { evidence* }\end{array}$ & Event & Outcome & Impact $†$ \\
\hline \multicolumn{5}{|l|}{ Employment } \\
\hline Kasimati $^{26}$ & $2+$ & 2004 OG Athens, Greece & Unemployment & $\downarrow$ \\
\hline $\mathrm{KPMG}^{27}$ & $2+$ & 2006 CG Melbourne, Australia & Unemployment & $\downarrow$ \\
\hline Baade $^{37} \ddagger$ & $2-$ & $\begin{array}{c}1984 \text { OG Los Angeles, CA, USA and } 1996 \\
\text { OG Atlanta, GA, USA }\end{array}$ & Employment & $\uparrow \downarrow$ \\
\hline Brunet $^{39}$ & $2-$ & 1992 OG Barcelona, Spain & Unemployment & $\downarrow$ \\
\hline Giesecke $^{38} \ddagger$ & $2-$ & 2000 OG Sydney, Australia & Employment & $\leftrightarrow$ \\
\hline Hotchkiss $^{29}$ & $2-$ & 1996 OG Atlanta & Employment & $\uparrow$ \\
\hline $\begin{array}{l}\text { Institute of Social and Economic } \\
\text { Research }\end{array}$ & $2-$ & 2001 SWOG Anchorage, AK, USA & Employment & $\uparrow$ \\
\hline $\mathrm{Kim}^{30}$ & $2-$ & 1988 OG Seoul, South Korea & Employment & $\uparrow$ \\
\hline Lybbert $^{32} \ddagger$ & $2-$ & 1980 and 1988 WO; 1984 and 1996 OG & Employment & $\uparrow$ \\
\hline Newby $^{24}$ & $2-$ & 2002 CG Manchester, UK & Unemployment & $\downarrow$ \\
\hline Smith $^{35}$ & Qualitative & 2002 CG Manchester & Employment & $\uparrow$ \\
\hline Tucker ${ }^{34}$ & $2-$ & 1984-2004 OG & Employment & $\uparrow$ \\
\hline \multicolumn{5}{|l|}{ Economic growth } \\
\hline Kasimati $^{26}$ & $2+$ & 2004 OG Athens & Economic growth & $\uparrow$ \\
\hline $\mathrm{KPMG}^{27}$ & $2+$ & 2006 CG Melbourne & Economic growth & $\uparrow$ \\
\hline Economics Research $\mathrm{A}^{28}$ & $2-$ & 1984 OG Los Angeles & Economic growth & $\uparrow$ \\
\hline Giesecke $^{38}$ & $2-$ & 2000 OG Sydney & Economic growth & $\downarrow$ \\
\hline $\begin{array}{l}\text { Institute of Social and Economic } \\
\text { Research }\end{array}$ & $2-$ & 2001 SWOG Anchorage & Economic growth & $\uparrow$ \\
\hline $\mathrm{Kim}^{30}$ & $2-$ & 1988 OG Seoul & Economic growth & $\uparrow$ \\
\hline Greater London Authority ${ }^{31}$ & $2-$ & 1992-2004 OG & $\begin{array}{l}\text { Economic growth and fixed } \\
\text { capital formation }\end{array}$ & $\uparrow$ \\
\hline Lybbert $^{32} \ddagger$ & $2-$ & 1980 and 1988 WO; 1984 and 1996 OG & Economic growth & $\uparrow \downarrow$ \\
\hline Pitts $^{33}$ & $2-$ & 1998 GG Amsterdam, the Netherlands & Economic growth & $\uparrow$ \\
\hline Sterken ${ }^{36}$ & $2-$ & 1984-1996 OG & Economic growth & $\leftrightarrow$ \\
\hline \multicolumn{5}{|l|}{ Other economic outcomes } \\
\hline Brunet $^{39}$ & $2-$ & 1992 OG Barcelona & Inflation & $\uparrow$ \\
\hline \multirow{2}{*}{ Greater London Authority ${ }^{31}$} & \multirow{2}{*}{$2-$} & \multirow{2}{*}{$1992-2004$ OG } & Income & $\uparrow \downarrow$ \\
\hline & & & Inflation & $\uparrow \downarrow$ \\
\hline \multirow{2}{*}{ Newby $^{24}$} & \multirow{2}{*}{$2-$} & \multirow{2}{*}{2002 CG Manchester } & Net income & $\uparrow$ \\
\hline & & & Financial difficulty & $\downarrow$ \\
\hline Preuss $^{40}$ & $2-$ & 2000 OG Sydney & Inflation & $\leftrightarrow$ \\
\hline \multirow{2}{*}{ Searle ${ }^{41}$} & \multirow{2}{*}{$2-$} & \multirow{2}{*}{2000 OG Sydney } & $\begin{array}{l}\text { Health and education } \\
\text { spending }\end{array}$ & $\downarrow$ \\
\hline & & & Recreation spending & $\uparrow$ \\
\hline \multicolumn{5}{|l|}{ Business } \\
\hline Berman $^{43}$ & $2-$ & 2000 OG Sydney & Stock market value & $\uparrow$ \\
\hline Mount $^{46}$ & $2-$ & 1988 WO Calgary, AB, Canada & Perceived benefits for business & $\uparrow$ \\
\hline O'Brien $^{45}$ & Qualitative & 2000 OG Sydney & $\begin{array}{c}\text { Development of a business } \\
\text { network }\end{array}$ & N/A \\
\hline O'Brien $^{44}$ & Qualitative & 2000 OG Sydney & Business network strategies & $\mathrm{N} / \mathrm{A}$ \\
\hline Smith $^{35}$ & Qualitative & 2002 CG Manchester & Business assistance & $\uparrow$ \\
\hline Veraros $^{42}$ & $2-$ & 2004 OG Athens & Stock market value & $\uparrow$ \\
\hline \multicolumn{5}{|l|}{ Tourism } \\
\hline \multirow{2}{*}{ Athanasopoulos ${ }^{68}$} & \multirow{2}{*}{$2+$} & \multirow{2}{*}{2000 OG Sydney } & Domestic tourist visits & $\leftrightarrow$ \\
\hline & & & Domestic business travel & $\uparrow$ \\
\hline \multirow{2}{*}{ Brunet $^{39}$} & $2-$ & & Tourist overnight stays & $\uparrow$ \\
\hline & $2-$ & 1992 OG Barcelona & Hotel occupancy & $\downarrow$ \\
\hline $\begin{array}{l}\text { Northwest Regional Development } \\
\text { Agency }{ }^{67}\end{array}$ & $2-$ & 2002 CG Manchester & $\begin{array}{l}\text { Tourist trips (UK and } \\
\text { international tourists) }\end{array}$ & $\uparrow \downarrow$ \\
\hline Giesecke $^{38}$ & $2-$ & 2000 OG Sydney & Tourist spending & $\uparrow \downarrow$ \\
\hline Kang $^{66}$ & $2-$ & 1988 OG Seoul & $\begin{array}{l}\text { Share of South East Asian } \\
\text { tourist market }\end{array}$ & $\uparrow$ \\
\hline & & $1992-2000$ OG & Tourist visitors & $\uparrow$ \\
\hline Greater London Authority ${ }^{31}$ & $2-$ & 1996 OG Atlanta & Number of conventions & $\uparrow$ \\
\hline & & 1996 OG Atlanta & Hotel occupancy & $\uparrow$ \\
\hline Spilling $^{64}$ & $2-$ & 1994 WO Lillehammer & Overnight visitors & $\uparrow$ \\
\hline & & & Tourist visits & $\downarrow$ \\
\hline $\begin{array}{l}\text { State of Utah Governor's Office of } \\
\text { Planning and Budget }{ }^{69}\end{array}$ & $2-$ & 1988 WO Calgary & Tourism revenue & $\uparrow$ \\
\hline & & 1996 OG Atlanta & Hotel occupancy & $\uparrow$ \\
\hline Teigland $^{65}$ & $2-$ & 1988-1994 WO & Tourist visits & $\uparrow \downarrow$ \\
\hline
\end{tabular}

Abbreviations: AG, Asian Games; CG, Commonwealth Games; GG, Gay Games; GWG, Goodwill Games; OG, Olympic Games; SWO, Special Winter Olympic Games; WO, Winter Olympic Games.

* Level of evidence as per web table $E$.

$\dagger \uparrow=$ increase; $\downarrow=$ decrease; $\leftrightarrow=$ no change; $\uparrow \downarrow=$ mixed impacts for this outcome; N/A=not applicable (i.e. the outcome cannot be described as a simple increase or decrease)

$\ddagger$ These economic studies did not use any estimated data. 
found that regions that focused on the development of a long term business network to generate better networking and market access fared better than areas that focused on short term benefits from attracting visitors. ${ }^{445}$ Business was perceived to have benefited from the 1988 Olympic Games in Calgary, AB, Canada ${ }^{46}$ and from business assistance offered during the 2002 Commonwealth Games in Manchester. ${ }^{35}$

\section{Impacts on transport and the environment}

Studies of five cities (Atlanta ${ }^{1847}$; Busan ${ }^{1748}$; Los Angeles, CA, USA ${ }^{49}$; Seattle, WA, USA ${ }^{50}$; and Sydney ${ }^{51}$ ) examined the impact of transport mitigation strategies put in place during major sports events, such as restrictions on car use, increased public transport availability, promotion of car sharing, and increased working hours flexibility. A fall in air pollution was reported in two cities: Atlanta ${ }^{18}$ and Busan (level 2+ ). ${ }^{17} \mathrm{~A}$ lower quality study in Busan reported an increase in pollution. ${ }^{48}$ Road traffic volume decreased in Atlanta and Busan,,$^{18474850}$ as did car journey time in Los Angeles and Sydney. ${ }^{4951}$ A small study ( $\mathrm{n}=12$ households) reported increased aircraft noise and night time wakings around the time of the Olympic Games among residents living close to the airports in Atlanta. ${ }^{52}$

\section{Impacts on volunteers}

Three studies examined the impacts of major multisports events on event volunteers. They reported that volunteers at the 2002 Manchester Commonwealth Games had a mix of positive and negative experiences ${ }^{53}$; no change in their desire to volunteer in the future ${ }^{5354}$; and no increase in sports participation. ${ }^{5354}$ However, one study did find that volunteers at the 1994 Winter Olympic Games in Lillehammer, Norway, and the 2000 Olympic Games in Sydney perceived an increase in their skills after volunteering. ${ }^{55}$

\section{Other impacts}

Demand for police services in Atlanta increased and recorded crime decreased during the 1996 Olympic Games (level 2+). ${ }^{56}$ Reported vandalism decreased after the 2002 Commonwealth Games in Manchester, whereas satisfaction with the local area, housing, and supermarket access increased..$^{24}$ There was consistent evidence from four Olympic cities (Barcelona, Atlanta, Sydney, and Athens) that house prices rose in host cities in comparison with other areas of the host country. ${ }^{313957}$

It has been suggested that the Calgary Winter Olympics in 1988 were associated with depopulation in the immediate area next to the games venues, ${ }^{58}$ but another study has reported increased migration to the wider host area for all north American Olympic events. ${ }^{32}$ In Atlanta, a new "urban camping" law was reported to have been used at the time of the Olympic Games to move homeless people away from the games environs. ${ }^{59}$
A study of the Olympic Games in Sydney in 2000 reported data suggesting that hosting the games was associated with centralisation of decision making and a loss of local democracy ${ }^{60}$ However, another study described enhanced community spirit and national pride following the games. ${ }^{61}$

Values among residents of the host country were found not to have changed after the 1994 Winter Olympics in Lillehammer. ${ }^{62}$ There was a reported decline in Catalan identification following the 1994 Barcelona Olympic Games, in contrast to increasing regional identification in other areas of Spain. ${ }^{63}$

The number of tourists visiting Lillehammer, ${ }^{6465}$ Atlanta, ${ }^{31}$ Seoul, ${ }^{66}$ and Barcelona ${ }^{39}$ increased during the respective Olympic or Winter Olympic Games. On the other hand, the number of tourists visiting Calgary during the 1988 Winter Olympic Games was largely unchanged ${ }^{65}$ and the number visiting Manchester during the 2002 Commonwealth Games decreased. ${ }^{67}$ The impact of the Olympic Games on tourist visits to Sydney in 2000 was mixed. ${ }^{3868}$ Hotel occupancy rates during the Olympic Games decreased in Barcelona ${ }^{39}$ and increased in Atlanta. ${ }^{69}$

\section{DISCUSSION}

There is little evidence that major multi-sport events held between 1978 and 2008 delivered health or socioeconomic benefits for the population of the host country. The evidence addressing each outcome comprises a relatively small number of poor quality studies, and there are large gaps in the range of outcomes evaluated, particularly with respect to health outcomes. Restrictions on use of cars and promotion of public transport during events may be followed by reductions in air pollution, and this relation may in turn be associated with a drop in hospital admissions for childhood asthma. The evidence also suggests that economic growth and unemployment may both be associated with events, but findings from the economic evaluations that used high quality data (that is, non-estimated data) contradict this.

Both the commissioning of studies and their publication could well be biased towards positive results. Given this fact and our review's extensive coverage of the published and unpublished literature, it is unlikely that we could have overlooked a large positive effect of major multi-sport events on health or on socioeconomic determinants of health. The available evidence does not refute expectations of a legacy, positive or negative, but it does establish that very little is known about the impacts of previous large multi-sport events and, therefore, the possible impacts of future events. This contrasts with official documentation used recently to promote such events. ${ }^{12}$

The potential impacts of major multi-sport events are multiple and encompass changes in health and in many of the socioeconomic determinants of health. In our analysis, however, no particular impact had a consistent pattern on outcomes across different events, nor was there evidence of a positive impact across a range 


\section{WHAT IS ALREADY KNOWN ON THIS TOPIC}

Cities hosting major multi-sport events are under increasing pressure to justify expenditure by creating a positive legacy for the host population; for example, in terms of improvements in employment levels, health, and the economy

No attempts have been made to bring together the large amount of research on the impact of major multi-sport events on host populations

\section{WHAT THIS STUDY ADDS}

There is little or no evidence that major multi-sport events held between 1978 and 2008 had positive impacts on the populations of cities that hosted these events

A positive health or socioeconomic benefit for the host population cannot be expected from future major multi-sport events

How the impacts of events are evaluated needs to improve to allow decision makers pitching for future events to make informed judgments on the basis of known effects and known areas of uncertainty

\section{Policy implications}

Decision makers should consider taking a different approach to the implementation of future events if the cost is to be justified by benefits to the population of the host country. Such approaches might include increasing democratic control of event related spending (for example, channelling funding through existing elected bodies), recasting the events as less costly and simpler sports events, or using impact assessment approaches to optimise the effects of the event "intervention."

Knowledge of the impacts of major multi-sport events might improve if evaluations of future events are based on a framework that details a "theory of change" for the event. ${ }^{76}$ Improved reporting of evaluations, use of suitable contemporaneous comparison groups (ideally within longitudinal studies), and inclusion of long term outcomes would all be likely to increase the quality of future evidence. Economic studies in particular would be improved if they used real time data instead of estimates and incorporated opportunity costs in their models.

\section{Conclusions}

The cost of hosting a major multi-sport event such as the Olympic Games or the Commonwealth Games has increased over the past two decades, to the extent that it has become difficult to justify the expenditure on the basis of entertainment or national showcasing alone. ${ }^{7}$ Cities competing to host events are now judged on the prospect of a long term positive legacy being generated for the host population, among other factors.

Our review found insufficient evidence to confirm or refute expectations about the health or socioeconomic benefits for the host population of previous major multi-sport events. Benefits from future events - such as the 2012 Olympic Games and Paralympic Games in London or the 2014 Commonwealth Games in Glasgow-cannot be expected to occur automatically. There is a lack of evidence on the impacts of major multi-sport events on the host population, and until decision makers include robust, long term evaluations as part of their design and implementation of events, it is unclear how the costs can be justified in terms of host population benefits.

Contributors: SM had the original idea for the review. GMCC, ST, and HT designed and planned the review. GMcC was the lead reviewer and ST was a co-reviewer. Both reviewers undertook study selection and appraisal, and data extraction and tabulation. HT provided advice on each aspect of the review methods. GMCC, ST, HT, JS, PH, DSM, and LB formed a review advisory group. JS and $\mathrm{GMCC}$ were responsible for searching the grey literature, and VH was responsible for database searching. Mary Robins, the staff at Glasgow University Library, and the staff of the Public Health Resource Unit library at NHS Greater Glasgow and Clyde assisted in the retrieval of articles. Adam Brown and Susie Palmer provided additional grey literature. Nigel Rice and Ken Gibb gave advice on the appraisal of economic studies. Erik Lenguerrand and Elena Sautkina assisted with translation of foreign language articles. GMCC, ST, and HT synthesised the data, and GMCC wrote the manuscript. All the authors critically revised the manuscript and approved the final version. The views expressed here are those of the authors and do not necessarily reflect the views of the Medical Research Council, the Chief Scientist Office at the Scottish Government Health Directorate, the University of Glasgow, or the NHS. GMCC is the guarantor. 
Funding: GMCC, ST, HT, VH, and LB were funded by the Chief Scientis Office at the Scottish Government Health Directorate as part of the Evaluating Social Interventions programme at the Medical Research Council Social and Public Health Science Unit (wbs

U.1300.00.002.00024.01). JS works as part of the Public Health Resource Unit at NHS Greater Glasgow and Clyde. PH and DSM are funded by the University of Glasgow. DSM is also partially funded by NHS Greater Glasgow and Clyde. This study was not commissioned and no project specific funding was received. The funders had no role in the study design; data collection, analysis, and interpretation; writing the manuscript; or the decision to submit the research for publication. Competing interests: GMCC is a member of the Scottish Socialist Party and was previously involved in a project to have a velodrome built in the west of Scotland. All authors have completed the Unified Competing Interest form at www.icmje.org/coi_disclosure.pdf (available on request from the corresponding author) and declare: (1) No financial support for the submitted work from anyone other than their employer; (2) No financial relationships with commercial entities that might have an interest in the submitted work; (3) No spouses, partners, or children with relationships with commercial entities that might have an interest in the submitted work; (4) No non-financial interests that may be relevant to the submitted work.

Ethics approval: No ethics approval was required for this study. Data sharing: No additional data available.

1 London candidate file. London 2012 Ltd, 2004.

2 People Place Passion. Glasgow 2014 Commonwealth Games candidate city file. 2007.

3 The Scottish Government. Glasgow 2014-delivering a lasting legacy for Scotland. A consultation paper.

2008. www.scotland.gov.uk/Publications/2008/02/14115955/0.

4 Department for Culture, Media and Sport. Before, during and after. Making the most of the London 2012 Games.

2008. www.culture.gov.uk/images/publications/

2012LegacyActionPlan.pdf.

5 Dahlgren G, Whitehead M. Policies and strategies to promote social equity in health. Institute of Futures Studies, 1991.

6 Weed M, Coren E, Fiore J, Mansfield L, Wellard I, Chatziefstathiou D, et al. A systematic review of the evidence base for developing a physical activity and health legacy from the London 2012 Olympic and Paralympic Games. Department of Health, 2009.

7 Wintour P. We would not have bid for games during recession, says Jowell. Guardian 13 November

2008. www.guardian.co.uk/uk/2008/nov/13/olympics2012recession.

8 Brown A, Massey J. Literature review: the impact of major sporting events. Manchester Institute for Popular Culture, Manchester Metropolitan University, 2001.

9 Horne J. The four "knowns" of sports mega-events. Leisure Studies 2007;26:81-96.

10 McCartney G. A systematic review of the health impact of major sporting events on the host population Glasgow. MRC Social and Public Health Sciences Unit, 2008.

11 Preuss $\mathrm{H}$. The impact and evaluation of major sporting events. Routledge, 2007.

12 Effective Public Health Practice Project. Quality assessment tool for quantitative studies. Effective Public Health Practice Project, 1998. http://nccmt.ca/uploads/registry/QATool.pdf.

13 Dixon-Woods M, Shaw RL, Agarwal S, Smith JA. The problem of appraising qualitative research. Qual Saf Health Care 2004;13:223-5.

14 Weightman A, Ellis S, Cullum A, Sander L, Turley R. Grading evidence and recommendations for public health interventions: developing and piloting a framework. Health Development Agency, 2005.

15 Popay J, Roberts H, Sowden A, Petticrew M, Arai L, Rodgers M, et al. Guidance on the conduct of narrative synthesis in systematic reviews. A product from the ESRC methods programme. Version 1. ESRC, 2006.

16 Shin EH. The Olympic Games and suicides: an analysis of the effects of the Seoul Olympiad on social integration in Korea. Toward one world beyond all barriers, English ed. Seoul Olympic Sports Promotion Foundation, 2000.

17 Lee JT, Son JY, Cho YS. Benefits of mitigated ambient air quality due to transportation control on childhood asthma hospitalization during the 2002 summer Asian games in Busan, Korea. J Air Waste Manage Assoc 2007; 57:968-73.

18 Friedman MS, Powell KE, Hutwagner L, Graham LM, Teague WG Impact of changes in transportation and commuting behaviors during the 1996 Summer Olympic Games in Atlanta on air quality and childhood asthma. JAMA 2001;285:897-905.
19 Simon HK, Stegelman M, Button T. A prospective evaluation of pediatric emergency care during the 1996 Summer Olympic Games in Atlanta, Georgia. Pediatr Emerg Care 1998;14:1-3.

20 Indig D, Thackway S, Jorm L, Salmon A, Owen T. Illicit drug-related harm during the Sydney 2000 Olympic Games: implications for public health surveillance and action. Addiction 2003;98:97-102.

21 MORI. The sports development impact of the Commonwealth Games 2002-post-games research. Final report. Research study conducted for UK Sport in Greater Manchester, Blackburn, Congleton and Liverpool. MORI, 2004.

22 Truno E. Barcelona: city of sport. Centre d'Estudis Olimpics, 1995.

23 Brown A, Massey I, Porter C. The sports development impact of the 2002 Commonwealth Games: post games report. Manchester Institute for Popular Culture, Manchester Metropolitan University, 2004.

24 Newby L. To what extent have the Commonwealth Games accelerated the physical, social, and economic regeneration of East Manchester? University of Glasgow, 2003.

25 Institute of Social and Economic Research. Economic impact of the 2001 Special Olympics World Winter Games, Alaska. Institute of Social and Economic Research, University of Alaska Anchorage, 2002.

26 Kasimati E, Dawson P. Assessing the impact of the 2004 Olympic Games on the Greek economy: a small macroeconometric model. Econ Model 2009;26:139-46.

27 KPMG. Economic impact study of the Melbourne 2006 Commonwealth Games: post-event analysis. Office of Commonwealth Games Coordination, 2006.

28 Economics Research A. Community economic impact of the 1984 Olympic Games in Los Angeles and Southern California. ERA, 1984

29 Hotchkiss IL, Moore RE, Zobay SM. Impact of the 1996 summer Olympic games on employment and wages in Georgia. Southern Econ / 2003;69:691-704.

30 Kim J-G, Rhee S-W, Yu J-C, Koo K-M, Hong J-D. Impact of the Seoul Olympic Games on national development. Korea Development Institute, 1989.

31 Greater London Authority. A lasting legacy for London? Assessing the legacy of the Olympic Games and Paralympic Games. GLA, 2007.

32 Lybbert TJ, Thilmany DD. Migration effects of Olympic siting: a pooled time series cross-sectional analysis of host regions. Ann Reg Sci 2000;34:405-20.

33 Pitts BG, Ayers EK. An analysis of visitor spending and economic scale on Amsterdam from the Gay Games V, 1998. International Journal of Sport Management 2001;2:134-51.

34 Tucker L. How does hosting the Olympic Games impact employment in the host city? Undergraduate student paper contest. Carleton College \& the Federal Reserve Bank of Minneapolis, 2006.

35 Smith A, Fox T. From "event-led" to "event-themed" regeneration: the 2002 Commonwealth Games legacy programme. Urban Stud 2007;44:1125-43.

36 Sterken E. Growth impact of major sporting events. European Sport Management Quarterly 2006;6:375-89.

37 Baade RA, Matheson V. Bidding for the Olympics: fool's gold? In: Barros CP, Ibrahimo M, Szymanski SE, eds. Transatlantic sport: the comparative economics of North American and European sports. Edward Elgar, 2002.

38 Giesecke I, Madden I. The Sydney Olympics, seven years on: an expost dynamic CGE assessment. Centre of Policy Studies, Monash University, 2007.

39 Brunet F. Economy of the 1992 Barcelona Olympic Games. International Olympic Committee, 1993.

40 Preuss H. The economics of staging the Olympics: a comparison of the Games 1972-2008. Edward Elgar, 2006.

41 Searle G. Uncertain legacy: Sydney's Olympic stadiums. European Planning Studies 2002;10:845-60.

42 Veraros N, Kasimati E, Dawson P. The 2004 Olympic Games announcement and its effect on the Athens and Milan stock exchanges. Applied Economics Letters 2004;11:749-53.

43 Berman G, Brooks R, Davidson S. The Sydney Olympic Games announcement and Australian stock market reaction. Applied Economics Letters 2000;7:781-4.

44 O'Brien DJ. Strategic business leveraging of a mega sport event: the Sydney 2000 Olympic Games experience. CRC for Sustainable Tourism, 2005.

45 O'Brien D, Gardiner S. Creating sustainable mega event impacts: networking and relationship development through pre-event training. Sport Management Review 2006;9:25-47.

46 Mount J, Leroux C. Assessing the effects of a mega-event: a retrospective study of the impact of the Olympic Games on the Calgary business sector. Festival Management \& Event Tourism 1994;2:15-23.

47 Potter CSI. Assessing the impacts of transportation on ambient air quality: the 1996 Atlanta Olympics. Transportation Research Board, 1998. 
48 Lee BK, Jun NY, Lee HK. Analysis of impacts on urban air quality by restricting the operation of passenger vehicles during Asian Game events in Busan, Korea. Atmos Environ 2005;39:2323-38.

49 Giuliano G. Changes in travel demand characteristics during the 1984 Los Angeles Olympics. Institute of Transportation Studies, University of California, 1986.

50 Hallenbeck ME. Traffic impacts during the Goodwill Games: final report, research project GC8719, task 29, Goodwill Games traffic impacts. Washington State Department of Transportation, Planning and Research, and Public Transportation Division, in cooperation with the US Department of Transportation, Federal Highway Administration, 1991.

51 Hensher DABA. Going for gold at the Sydney Olympics: how did transport perform? Institute of Transport Studies, Australian Key Centre in Transport Management, the University of Sydney and Monash University, 2001.

52 Fidell S, Pearsons K, Tabachnick BG, Howe R. Effects on sleep disturbance of changes in aircraft noise near three airports. J Acoust Soc Am 2000;107:2535-47.

53 Lumsdon L. An evaluation of the motivations, expectations and experiences of volunteers prior to and during the XVII Commonwealth Games, Manchester, UK, 25th July-4th August 2002 Report 2: qualitative analysis. Manchester Metropolitan University and UK Sport, 2003.

54 Downward PM, Ralston R. The sports development potential of sports event volunteering: insights from the XVII Manchester Commonwealth Games. European Sport Management Quarterly 2006;6:333-51.

55 Kemp S. The hidden workforce: volunteers' learning in the Olympics. Journal of European Industrial Training 2002;26:109-16.

56 Decker SH, Varano SP, Greene JR. Routine crime in exceptional times: the impact of the 2002 Winter Olympics on citizen demand for police services. J Crim Justice 2007;35:89-101.

57 Halifax Plc. House prices in East End rise after Olympic win (press release).

2007. www.easier.com/32562-house-prices-in-east-end-rise-afterolympic-win.html.

58 Hiller HH, Moylan D. Mega-events and community obsolescence: redevelopment versus rehabilitation in Victoria Park East. Can J Urban Res 1999;8:47-81.

59 Hopkins E, Nackerud L. An analysis of Atlanta's ordinance prohibiting urban camping: passage and early implementation. Journal of Social Distress and the Homeless 1999;8:269-89.

60 Owen K. The Sydney 2000 Olympics and urban entrepreneurialism: local variations in urban governance. Aust Geogr Stud 2002;40:323-36.

61 Waitt G. The Olympic spirit and civic boosterism: the Sydney 2000 Olympics. Tourism Geographies 2001;3:249-78.

62 Kolstad A, Rundmo T, Svarva K. The consequences of the Olympic Games on the host city residents' value system. Corpus, Psyche et Societas 1995;2:85-94
63 Hargreaves JER. Freedom for Catalonia? Catalan nationalism, Spanish identity and the Barcelona Olympic Games. Cambridge University Press, 2000.

64 Spilling OR. Mega-event as strategy for regional development: the case of the 1994 Lillehammer Winter Olympics. Entrepreneurship \& Regional Development 1996;8:321-44.

65 Teigland J. Mega-events and impacts on tourism: the predictions and realities of the Lillehammer Olympics. Impact Assessment and Project Appraisal 1999;17:305-17.

66 Kang Y-S, Perdue R. Long-term impact of a mega-event on international tourism to the host country: a conceptual model and the case of the 1988 Seoul Olympics. Journal of International Consumer Marketing 1994;6:205-25.

67 Northwest Regional Development Agency. Commonwealth Games benefits study. Final report. Faber Maunsell, 2004.

68 Athanasopoulos G, Hyndman RJ. Modelling and forecasting Australian domestic tourism. Tourism Management 2008;29:19-31.

69 State of Utah Governor's Office of Planning and Budget. 2002 Olympic Winter Games. Economic, demographic and fiscal impacts. State of Utah Governor's Office of Planning and Budget, 2000.

70 Centre on Housing Rights and Evictions. Fair play for housing rights: mega-events, Olympic Games and housing rights-opportunities for the Olympic Movement and others.

2007. www.sheltercentre.org/library/fairplay+housing+rights+mega +events+olympic+games+housing+rights+opportunities+olympic +movement+others.

71 Preuss H. Problematizing arguments of the opponents of Olympic Games. In: Barney RK, Wamsley KG, Martyn SG, MacDonald GH, eds. Global and cultural critique: problematizing the Olympic Games. Centre for Olympic Studies, University of Western Ontario, 1998:197-218.

72 Crompton JL. Economic impact analysis of sports facilities and events: eleven sources of misapplication. Journal of Sport Management 9:14-35.

73 Murphy NM, Bauman A. Mass sporting and physical activity eventsare they "bread and circuses" or public health interventions to increase population levels of physical activity? J Phys Act Health 2007;4:193-202.

74 New Economics Foundation. Fool's gold: how the 2012 Olympics is selling East London short, and a 10 point plan for a more positive legacy. New Economics Foundation, 2008.

75 Vila G, Gavalda J. The Barcelona Model under scrutiny: social risks of urban transformation. International Sociological Association, 2006.

76 Connell JP, Kubisch AC, Schorr LB, Weiss CH. New approaches to evaluating community initiatives. Vol. 1. Concepts, methods and contexts. Aspen Institute, 1995.

Accepted: 2 March 2010 